\title{
Evaluating the Human Machine Interface Experience in Industrial Workplaces
}

\author{
Erik Aranburu \\ Mondragon Unibertsitatea \\ Mondragon, Gipuzkoa (Spain) \\ earanburu@mondragon.edu
}

\author{
Ganix Lasa \\ Mondragon Unibertsitatea \\ Mondragon, Gipuzkoa (Spain) \\ glasa@mondragon.edu
}

\author{
Jon Kepa Gerrikagoitia \\ Ideko S. Coop \\ Elgoibar, Gipuzkoa (Spain) \\ jkgerrikagoitia@ideko.es
}

\begin{abstract}
The new era of the user experience is focused on the hedonic and emotional aspects of the interaction between the user and the machine, beyond the pragmatic vision of the usability analysis. This new approach has become the main goal of many products, interfaces and service designs. However, in the industrial contexts, where Human Machine Interface (HMI) design traditionally has been focused on usability optimization and task efficiency, the user experience has hardly been studied. In the new industrial era, referred as industry 4.0, the connected intelligent systems would need to communicate and cooperate with the humans to improve the quality and productivity. So, the knowledge that user experience discipline can provide is crucial. In view of this situation, this paper presents an evaluation method of the employees' experience while interacting with the industrial HMls, in order to optimize the interactive workplaces. As a result, this new framework enables the identification of critical issues on the interaction experience and facilitates the creation of new HMI solutions.
\end{abstract}

User experience evaluation; usability; emotions; motivation-goals; HMI; industrial workplaces

\section{INTRODUCTION}

The Human-Computer Interaction $(\mathrm{HCl})$ field has recently entered in a new era, the so-called "third wave of interaction", where the main focus is based on designing for the User Experience (UX) (Bødker, 2006). After the era of usability and usercentred design, digital systems' design has begun to focus on emotional and hedonic aspects, beyond the pragmatic and instrumental aspects that this area has traditionally aimed (Hassenzahl, 2010). The approach of the user experience is based on personal and subjective aspects of the interaction, defined as a dynamic story capable of creating emotions (Hassenzahl et al., 2015).

As a consequence, nowadays UX design has become the goal of many product and services in the consumer market. However, in the industrial environment, the UX in the use of HMls has rarely been studied.

Design in such technological field as the machine-tool industry has traditionally focused on the task efficiency and the improvement of productive processes. Nevertheless, with the advent of the new manufacturing industry era, the so-called industry 4.0, the value of design needs to evolve. The integration of new connected cyber-physical systems originates a wide range of innovation possibilities, but requires an optimized communication between the machines and the users (Gorecky, 2014). In this new situation, the knowledge that user experience discipline can provide is crucial. The huge amount of data gathered needs to be made visual according to the needs of the users, so they can exploit the whole potential that these new technologies offer. A system adapted to the user and designed for a positive experience, with the functional optimization and the efficiency in task execution will generate positive emotions on the user; consequently, influencing the human knowledge, learning processes, decision making and intelligence (Davidson et al., 2003). In addition, it is known that positive emotions can increase the user motivation and implication (Isen, 2001). Therefore, the UX and the Human Machine Interfaces (HMI) should be considered a suitable area to generate affect, efficiency, satisfactory interactions and guarantee learning processes in such a complex system like the industrial machinery. Due to this situation, the development of new HMls is considered as one of the key challenges for the new industrial service solutions (Pfeiffer, 2016). 
Nowadays, there is a big necessity within the methods and tools intended for materialization and optimization of machine-tool interfaces from the perspective of the user experience and emotional development of the employees (Ardito et al., 2014). Tools such as the Eyeface (Lasa et al., 2015) unleash the research work related to methods and tools based on user experience, covering the necessity that was mentioned before.

In this context, this article describes a theoretical framework that defines an evaluation method of the employees' experience in the interaction with industrial interfaces, facilitating the identification of critical issues and the creation of new HMI solutions.

\section{USER EXPERIENCE}

Since the 70's, the experience-driven design has been a subject of study as the Kansei engineering shows (Namagachi 2002). It became a concept of big relevance in the late 90's, probably owing to the creation of Design and Emotions Society in 1999 (Kaasinen et al., 2015). This society was created aiming to introduce emotional aspects into the design processes. The next years, many authors acknowledged the relevance of the design for experiences and emotions (Jordan, 2000; Desmet, 2003; Norman, 2004; Forlizzi \& Battarbee, 2004).

Ever since, the user experience concept has continued gaining relevance in the $\mathrm{HCl}$ discipline (Kashfi et al., 2016), but during the years several practitioners have been struggling to define a widely accepted definition. In order to establish a general agreement, two main ways have been followed: reviewing UX research (Bargas- Avila \& Hornbæk, 2011; Law, van Schaik, \& Roto, 2014) and surveying UX practitioners (Law et al., 2009; Lallemand, 2015). According to Law et al. (2009) survey, there are three main reasons that makes difficult to get an agreed definition: the arbitrariness in the inclusion of the variables of the experience, the malleability of the analysis aspects and the diversity of the focus of the theoretical models. In the attempt at solving the critical uses of the UX, they asked several practitioners to choose a definition among 5 options. As a conclusion, the survey showed that the definition proposed by Hassenzahl \& Tractinsky (2006) was the most agreed one, which declares UX as "A consequence of a user's internal state (predispositions, expectations, needs, motivation, mood, etc.) the characteristics of the designed system (e.g. complexity, purpose, usability, functionality, etc.) and the context (or the environment) within which the interaction occurs (e.g. organisational/social setting, meaningfulness of the activity, voluntariness of use, etc.)". Nonetheless, they concluded that the terms need further explanations and a more precise definition of the elements of the experience. Similarly, Lallemand (2015) replicated the survey to observe if the UX term had evolved during the following years. The survey showed that the definition by Hassenzahl \& Tractinsky (2006) was again the most preferred one. As a result, they declared that the terms of the definition are validated within the $\mathrm{HCl}$ community, so this framework has been elaborated based on the mentioned definition.

Nevertheless, there is still a necessity of a further explanation of the elements of the experience and the way to evaluate them, which as the definition shows, depend on the user's internal state, context and the designed system. Besides, these UX knowledge has rarely been studied in industrial $\mathrm{HMI}$ workplaces. As a consequence, this framework aims to fill the gap between the UX evaluation methods and the industrial HMls.

\section{UX EVALUATION OF HMIS IN INDUSTRIAL WORKPLACES}

On the basis of the previous definition, this framework defines the main elements that influence in the experience of the employees in the interaction with industrial HMls, and the procedure to evaluate them. The experience happens in an industrial workplace, where the characteristics and conditions of the place affect directly the resulting evaluation. The resulting experience depends on the employee's characteristics, needs and previous experiences, on the functionality, purpose and usability of the designed HMI and finally in the interaction between them (Figure 1). During the interaction of the tasks execution, both pragmatic and hedonic qualities are evaluated, analysing how the systems aesthetics, information architecture (IA) and usability affect on the employee's emotions and motivation-goals fulfilment.

\section{EVALUATION PROCEDURE}

In order to evaluate the mentioned elements of the experience, a dynamic evaluation procedure has been defined, where the elements are analysed over time. The main reason to do so is because the internal and emotional state of the employee could change during the experience, as well as the circumstances of the workplace or the system itself. As a consequence, the experience is evaluated in three main phases: before the interaction, during the interaction and after the interaction (Figure 2)

In the first phase, the workplace, the HMI and the employee are analysed and the motivation-goals are defined. The experience occurs in a specific time at a particular place, so the environment is critical for the experience. 


\section{USER EXPERIENCE IN INDUSTRIAL WORKPLACES}

\section{INDUSTRIAL WORKPLACE}

THREE LEVELS OF INTERACTION

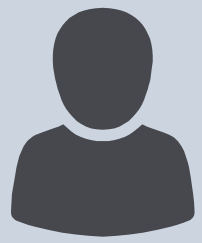

Emotions

Motivation-goals

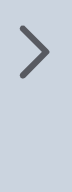

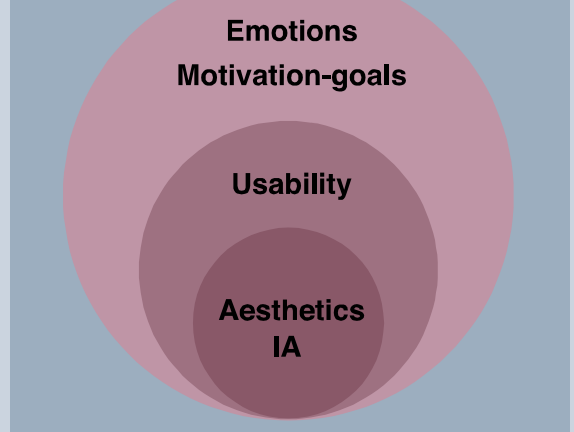

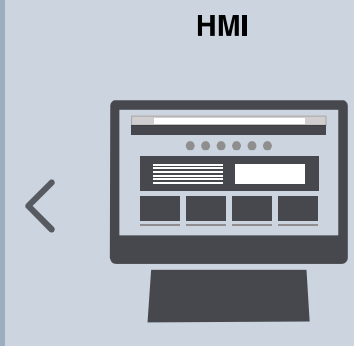

Figure 1: User experience in industrial workplaces

There are several aspects within the interaction context that influence in the resulting experience of the user, from elements close to the interactive systems to the elements with wider scope such as the brand (von Saucken \& Gomez, 2014). In this approach, the following factors have been proposed to evaluate the context of the experience: (i) the analysis of the machine where the HMI is located, (ii) the co-existing products that are necessary to interact with the HMI (e.g. a keyboard or a mouse), (iii) employees' assessment of the workplace and its social environment and (iv) the employees' perception of the brand and values of company. Then the employees of the HMl are analysed, because the previous experiences or the opinions about the HMl could be determinant in the resulting experience. Therefore, understanding the user before analysing the interaction is crucial to comprehend the experience. Then, the motivationgoals are defined, which refer to the psychological needs of the users. Most of the positive experiences we live through and remember are related to the compliance of ten universal needs (Sheldon et al., 2001), so every interaction has an intrinsic motivation behind and its fulfilment determines how the experience has been. In the case of the experiences in the interaction of industrial HMls, the following ones have been considered as determining: autonomy, competence, relatedness, security and stimulation. In order to guide the motivations to the application in industrial environments, they have been adapted and defined as Motivation-goals in industrial HMls (Table 1).

So, the design and development teams would have to seek the fulfilment of these Motivation-goals to evoke positive experiences in industrial HMls.

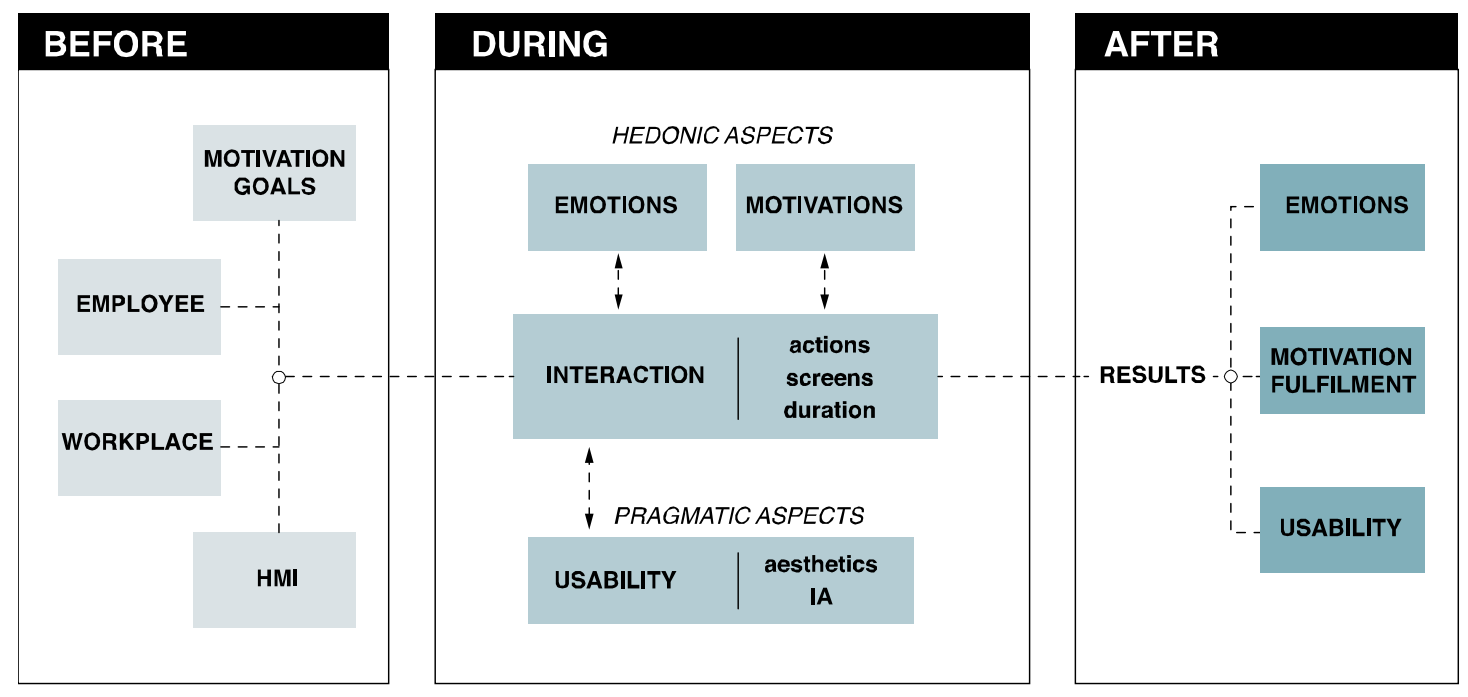

Figure 2: UX evaluation procedure for industrial workplaces 
To finish with the first phase, before analysing how the system behaves during the interaction, the aim is to evaluate the pragmatic and instrumental quality of the HMI. To do so, this framework proposes the UXER tool (Lasa et al., 2017), a tool based on the heuristic principles of usability, which provides an assessment of the HMI based on the judgement of a UX expert evaluator.

Table 1: Motivation-goals, adapted from Sheldon et al. (2001)

\begin{tabular}{|c|c|}
\hline $\begin{array}{l}\text { MOTIVATION - } \\
\text { GOALS }\end{array}$ & Factors to evaluate the fulfilment \\
\hline Autonomy & $\begin{array}{l}\text { Task accomplishment in an independent } \\
\text { way, without others' help and advices } \\
\text {. Possibility to control the rhythm of interaction } \\
\text {. Freedom to interact in their own way and } \\
\text { personalize the navigation }\end{array}$ \\
\hline Competence & $\begin{array}{l}\text { Capable, effective and qualified to complete } \\
\text { the tasks } \\
\text { Task accomplishment in an intuitive way } \\
\text { Task accomplishment in the shortest time } \\
\text { possible }\end{array}$ \\
\hline Relatedness & $\begin{array}{l}\text { Care of the system to the employees' interests } \\
\text { Anticipation of the system to the employee's } \\
\text { needs } \\
\text { Close and friendly communication of the } \\
\text { system }\end{array}$ \\
\hline Security & $\begin{array}{l}\text { Security and a feeling of being in control of } \\
\text { the situation. } \\
\text {. Lack of threats and uncertainties during the } \\
\text { task accomplishment } \\
\text {. Trust with the system }\end{array}$ \\
\hline Stimulation & $\begin{array}{l}\text { Stimulation of the senses while interacting } \\
\text { with the system } \\
\text { Attraction with the aesthetics of the system } \\
\text { Feeling of new sensations while interacting } \\
\text { with the system }\end{array}$ \\
\hline
\end{tabular}

In the second phase, the employee's behaviour and performance during specific tasks execution are evaluated. For that purpose, the actions, screens and duration of the task execution are gathered, defining their influence in the hedonic (emotions and motivations) and pragmatic (usability, considering information architecture and aesthetics) qualities. The actions are specified in a chronological order and should describe a specific objective (e.g. create a new group of tools or set an alarm), together with the screens where the actions are taking place. With the action description, the duration of each one and the usability issues during their performance are described. Then, the consequence of these issues in the employees' emotions and motivation-goals fulfilment is defined, based on the expert's observation of the task performance.

Finally, in the third phase, the employee's perception of the emotions and motivations fulfilment is collected, as well as a report about critical usability issues. This framework proposes the Panas $X$ questionnaire (Watson, 1999) to assess the emotions they felt during the experience. To evaluate the fulfilment of the motivation-goals, the users assess the factors of each motivation, as described in Table 1.

\section{CONCLUSIONS}

The paper presents a theoretical framework to evaluate the experience of the employees in the interaction with the industrial HMls. It proposes a dynamic evaluation process considering both pragmatic and hedonic aspects of the experience. The proposed evaluation method allows detecting critical issues of the interaction and facilitates the proposition of new solutions that improve the employees' experiences. The new approach provides a definition of the key elements of the experience and proposes the way to evaluate them. As a result, it fills the gap of the current methods and tools for the optimization of employees' experience with industrial HMIs. Thus, machine-tool companies will have the opportunity to evaluate the experience in their digital environments and detect critical issues that affect on the employees' interaction with the HMI. These evaluations will help on developing new HMI solutions that accelerate productive processes and increase the efficiency, and will help making the employees feel more autonomous, competent, related to the system, safe and stimulated.

Future work should be focused on carrying out different experimentations to see how the proposed procedure behave. This evaluation will help to validate the framework and to demonstrate its contribution on the creation of new HMI solutions. These experimentations will be carried out in both real and simulated contexts, to see how the framework works in different environments, because this factor could be critical in the evaluation of the experiences in industrial workplaces. 


\section{REFERENCES}

Ardito, C., Buono, P., Caivano, D., Costabile, M. F., \& Lanzilotti, R. (2014). Investigating and promoting UX practice in industry: An experimental study. International Journal of Human-Computer Studies, 72(6), 542-551. doi: 10.1016/j.ijhcs.2013.10.004

Bødker, S. (2006, October). When second wave $\mathrm{HCl}$ meets third wave challenges. In Proceedings of the 4th Nordic conference on Human-computer interaction: changing roles (pp. 1-8). ACM.

Davidson, R. J., Scherer, K. R., \& Goldsmith, H. (2003). Handbook of affective sciences. Oxford University Press.

Desmet P. (2003) Measuring Emotion: Development and Application of an Instrument to Measure Emotional Responses to Products. In: Blythe M.A., Overbeeke K., Monk A.F., Wright P.C. (eds) Funology. Human-Computer Interaction Series, vol 3. Springer, Dordrecht. doi: 10.1007/1-40202967-5_12

Gorecky, D., Schmitt, M., Loskyll, M., \& Zühlke, D. (2014, July). Human-machine-interaction in the industry 4.0 era. In Industrial Informatics (INDIN), 2014 12th IEEE International Conference on (pp. 289-294). IEEE. doi: 10.1109/INDIN.2014.6945523

Hassenzahl, M. (2010). Experience design: Technology for all the right reasons. Synthesis Lectures on Human-Centered Informatics, 3(1), 195. doi: $\underline{10.2200 / S 00261 E D 1 V 01 Y 201003 H C l 008}$

Hassenzahl, M., Wiklund-Engblom, A., Bengs, A., Hägglund, S., \& Diefenbach, S. (2015). Experience-oriented and product-oriented evaluation: psychological need fulfillment, positive affect, and product perception. International journal of human-computer interaction, 31(8), 530-544. doi:10.1080/10447318.2015.1064664

Jordan, P. W. (2000). The four pleasures-a framework for pleasures in design. In Proceedings of Conference on Pleasure Based Human Factors Design, Groningen. The Netherlands: Philips Design.

Kaasinen, E., Roto, V., Hakulinen, J., Heimonen, T., Jokinen, J. P., Karvonen, H., ... \& Tokkonen, H. (2015). Defining user experience goals to guide the design of industrial systems. Behaviour \& Information Technology, 34(10), 976-991. doi: 10.1080/0144929X.2015.1035335

Kashfi, P., Feldt, R., Nilsson, A., \& Svensson, R. B. (2016, August). A Conceptual UX-Aware Model of Requirements. In International Conference on Human-Centred Software Engineering (pp. 234245). Springer International Publishing. doi: 10.1007/978-3-319-44902-9_15
Lasa, G., Justel, D., \& Retegi, A. (2015). Eyeface: A new multimethod tool to evaluate the perception of conceptual user experiences. Computers in Human Behavior, 52, 359-363. doi: 10.1016/j.chb.2015.06.015

Law, E. L. C., van Schaik, P., \& Roto, V. (2014). Attitudes towards user experience (UX) measurement. International Journal of HumanComputer Studies, 72(6), 526-541. doi: 10.1016/j.ijhcs.2013.09.006

Nagamachi, M. (2002). Kansei engineering as a powerful consumer-oriented technology for product development. Applied ergonomics, 33(3), 289-294. doi: 10.1016/S0003-6870(02)00019-4

Pfeiffer, Thies. Empowering User Interfaces for Industrie 4.0. 5, s.I. : IEEE, 2016, Proceedings of the IEEE, Vol. 104, págs. 986-996. doi: 10.1109/JPROC.2015.2508640

Roto, V., Kaasinen, E., Heimonen, T., Karvonen, H., Jokinen, J. P., Mannonen, P., ... \& Kymäläinen, T. (2017, May). Utilizing Experience Goals in Design of Industrial Systems. In Proceedings of the 2017 $\mathrm{CHI}$ Conference on Human Factors in Computing Systems (pp. 6993-7004). ACM. doi: 10.1145/3025453.3025620

Sheldon, K. M., Elliot, A. J., Kim, Y., \& Kasser, T. (2001). What is satisfying about satisfying events? Testing 10 candidate psychological needs. Journal of personality and social psychology, 80(2), 325. doi: $10.1037 / 0022-$ 3514.80.2.325

Von Saucken, C., \& Gomez, R. (2014). Unified user experience model enabling a more comprehensive understanding of emotional experience design. In Proceedings of the 9th International Conference on Design and Emotion: The Colors of Care (pp. 631-640). Universidad de Los Andes.

Watson, D., \& Clark, L. A. (1999). The PANAS-X: Manual for the positive and negative affect schedule-expanded form. 